Revista Tecnologia e Ambiente, v. 23, 2017, Criciúma, Santa Catarina/SC

ISSN Eletrônico 2358-9426 e ISSN Impresso 1413-8131

\title{
AVALIAÇÃO DA EROSIVIDADE DE CHUVAS PARA O VALE DO RIO ITAJAÍ, SC
}

\section{EVALUATION OF RAINFALL EROSIVITY FOR THE ITAJAÍ RIVER VALLEY, SC}

\section{Álvaro José Back}

Engenheiro Agrônomo, Pesquisador da Empresa de Pesquisa Agropecuária e Extensão Rural de Santa Catarina (EPAGRI), Professor do Programa de Pós-Graduação em Ciências Ambientais da Universidade do Extremo Sul Catarinense PPGCA/UNESC. E-mail: ajb@epagri.sc.gov.br

\section{Fabiane Nunes} Gonçalves

Engenheira Ambiental, Mestranda do Programa de Pós-Graduação em Ciências Ambientais, Universidade do Extremo Sul Catarinense PPGCA/UNESC. E-mail: fabianenunes@yahoo.co m.br

\section{RESUMO}

A erosão hídrica superficial é um dos grandes problemas ambientais, que causa degradação das terras agrícolas, contaminação dos recursos hídricos e assoreamento dos reservatórios. Este trabalho teve como objetivo analisar os dados dos pluviogramas das estações de Itajaí e Indaial, localizadas na Bacia do Rio Itajaí, com a finalidade de avaliar a erosividade das chuvas e ajustar as equações para estimar o índice de erosividade a partir das médias pluviométricas da região. A metodologia usada para a determinação da erosividade da chuva foi de acordo com Wischmeier \& Smith (1978), baseado na energia cinética da chuva e na intensidade máxima em 30 minutos. Foram ajustadas equações de regressão dos modelos linear e potencial com os valores médios de $\mathrm{EI}_{30}$ e da do coeficiente de chuva (Rc), adotando o modelo que apresentou maior coeficiente de determinação. Com base na série dos dados pluviométricos foram determinados os valores de erosividade média mensal e anual e sua distribuição ao longo do ano para cada estação. Para ambas as estações a equação linear mostrou-se mais indicada, sendo obtidas as equações $\mathrm{EI} 30=40,56 \mathrm{Rc}+68,74\left(\mathrm{R}^{2}=0,7090\right)$ e $28,701 \mathrm{Rc}+13,54\left(\mathrm{R}^{2}=0,8152\right)$, respectivamente para Indaial e Itajaí. O valor médio do Índice de Erosividade (R) para Indaial é de 7025,0 $\mathrm{MJ} \mathrm{mm} \mathrm{ha}^{-1} \mathrm{~h}^{-1} \mathrm{ano}^{-1}$, e para Itajaí de $4756,3 \mathrm{MJ} \mathrm{mm} \mathrm{ha}^{-1} \mathrm{~h}^{-1} \mathrm{ano}^{-1}$.

Palavras-chave: erosão; sedimentos; chuvas.

\section{ABSTRACT}

The surface erosion is a major environmental problem, which causes degradation of agricultural land, pollution of water resources, silting of reservoirs. This study aimed to analyze the pluviograms of Itajaí and Indaial stations located in the basin of the Itajaí river, in order to evaluate the erosivity and adjust the equations to estimate erosivity index from the average rainfall in the region. The methodology used to determine the rainfall erosivity was according to Wischmeier \& Smith (1978), based on the kinetic energy of the rain and the maximum intensity in 30 minutes. Regression equations were adjusted for linear and potential models with the average values of $\mathrm{EI}_{30}$ and the rainfall coefficient (Rc), adopting the model with the highest coefficient of determination. Based on the series of rainfall data values were determined monthly and yearly average and its distribution throughout the year for each season. For both stations the linear equation was more suitable, and obtained the equationsEI30 $=40.56 \mathrm{Rc}+68.74\left(\mathrm{R}^{2}=0.7090\right)$ and $\mathrm{Rc}=28.701 \mathrm{Rc}+13.54\left(\mathrm{R}^{2}=0.8152\right)$, respectively for Indaial and Itajaí. The average value of Erosivity Index $(\mathrm{R})$ for Indaial is $7025.0 \mathrm{MJ} \mathrm{mm} \mathrm{ha}^{-1} \mathrm{~h}^{-1}$ year-1, and Itajaí $4756.3 \mathrm{MJ} \mathrm{mm} \mathrm{ha}^{-1} \mathrm{~h}^{-1} \mathrm{yr}^{-1}$.

Keywords: erosion; sediments; rains. 


\section{INTRODUÇÃO}

A erosão do solo é considerada um dos maiores problemas ambientais, responsável pela degradação dos solos, ocasionando prejuízos à produção agrícola e problemas de contaminação e poluição dos recursos hídricos e assoreamento de rios, lagos e reservatórios (Cassol et al., 2008). Estima-se que em média há perda de 1 a $2 \%$ dos volumes dos reservatórios em função da sedimentação. Esse assoreamento dos rios e reservatórios causa diminuição da vida útil dos reservatórios, redução na capacidade de regularização da vazão, aumento dos custos de produção de energia elétrica, como também prejudica a navegação nos cursos d'água e prejudica a fauna aquática. A erosão hídrica é um dos fatores que mais tem contribuído para a redução na produtividade agrícola, sendo acelerada pelo uso de práticas inadequadas de cultivo, que acarretam a exposição do solo aos agentes erosivos.

Dentre os tipos de erosão destaca-se a erosão hídrica superficial, que é provocada pelo impacto da chuva no solo e pelo escoamento superficial. A erosão hídrica superficial está associada diretamente com a intensidade da chuva e com as características do solo, como capacidade de infiltração, declividade da superfície, cobertura do solo, tipo de solo, entre outras.

Considerando os efeitos da chuva sobre o solo, a característica de maior influência no fenômeno erosivo é a intensidade, seguida da duração, que é o seu complemento e determina a chuva total. Pruski (2009) afirma que no processo de ocorrência de erosão hídrica, mais importante que os totais anuais precipitados, é a distribuição do tamanho, a velocidade e a energia cinética das gotas e a intensidade, duração e frequência da chuva, sendo o conjunto destes fatores conhecido como erosividade da chuva.

A energia cinética da chuva determina a erosividade, que corresponde à habilidade da chuva em causar erosão. É o parâmetro mais utilizado por diversos autores para predizer a perda de solo. Para determinação do potencial erosivo é necessário conhecer os parâmetros de erosividade e as características das gotas de chuva, que variam no tempo e no espaço.

Nos estudos dos processos erosivos podem ser adotados modelos com equações matemáticas para estimar as perdas de solo e avaliar os fatores que causam a erosão hídrica bem como estimar as perdas de solo e, dessa forma, avaliar as práticas de manejo do solo e planejamento ambiental. Dentre estes modelos destaca-se a Equação Universal de Perdas de Solo - USLE (Wischmeier \& Smith, 1958). A USLE é um modelo de erosão projetado para predizer a média de perdas de solo ao longo do tempo considerando o escoamento superficial de áreas especificadas em condições de manejo também especificadas. A USLE é constituída pelos principais fatores que causam a erosão hídrica, dentre os quais o fator erosividade das 
chuvas (R), que é um índice numérico que expressa a capacidade da chuva, esperada em dada localidade, de causar erosão em uma área sem proteção.

A erosividade das chuvas é determinada através de fatores como distribuição do tamanho, velocidade de queda, número, momento e energia cinética das gotas e também a intensidade, duração e frequência da chuva. É expressa como uma função potencial da intensidade de precipitação. Os primeiros estudos para determinar a energia cinética das gotas de chuva foram realizados por Wischmeier \& Smith em 1960, os quais propuseram o fator Erosividade da chuva $(\mathrm{R})$ incorporado à USLE, que representa o produto da energia cinética de cada chuva e sua intensidade máxima observada em 30 minutos.

$\mathrm{Na}$ determinação dos índices de erosividade é fundamental a existência de uma série histórica de dados pluviográficos. Quando, em determinada região, são escassos dados de chuva obtidos a partir de pluviógrafos, o cálculo do índice de erosividade pode ser feito por correlações e uso de equações de regressão entre os índices de erosividade e dados pluviométricos (Carvalho, 1987). Na bacia do Rio Itajaí existem diversos pluviômetros instalados com longas séries de precipitação, no entanto, existe carência de informações por parte destes. Esse trabalho teve como objetivo analisar as séries disponíveis de dados pluviográficos de Indaial e Itajaí para estimar o fator erosividade de chuvas e ajustar a equação para estimativa da erosividade das chuvas com dados dos pluviômetros existentes da região.

\section{MATERIAL E MÉTODOS}

Foram utilizadas as séries históricas das estações pluviográficas e pluviométricas de Itajaí e Indaial, conforme Tabela 1. As séries de dados pluviográficos existentes são relativamente curtas e com algumas falhas, por isso forma usados os dados dos pluviômetros para obter as médias de precipitação mensais mais representativas.

Tabela 1: Localização as estações e período de dados utilizados

\begin{tabular}{lccccc}
\hline Estação & $\begin{array}{c}\text { Latitude } \\
(\mathrm{S})\end{array}$ & $\begin{array}{c}\text { Longitude } \\
(\mathrm{W})\end{array}$ & $\begin{array}{c}\text { Altitude } \\
(\mathrm{m})\end{array}$ & Série de pluviógrafo & Série de pluviômetro \\
\hline Indaial & $26^{\circ} 57^{\prime}$ & $49^{\circ} 17^{\prime}$ & 76 & $1970-1983$ & $1970-2015$ \\
Itajaí & $26^{\circ} 54^{\prime}$ & $48^{\circ} 38$ & 5 & $1984-1999$ & $1984-2015$ \\
\hline
\end{tabular}

Fonte: adaptado de ANA (2009). 
Figura 1: Localização da área de estudo
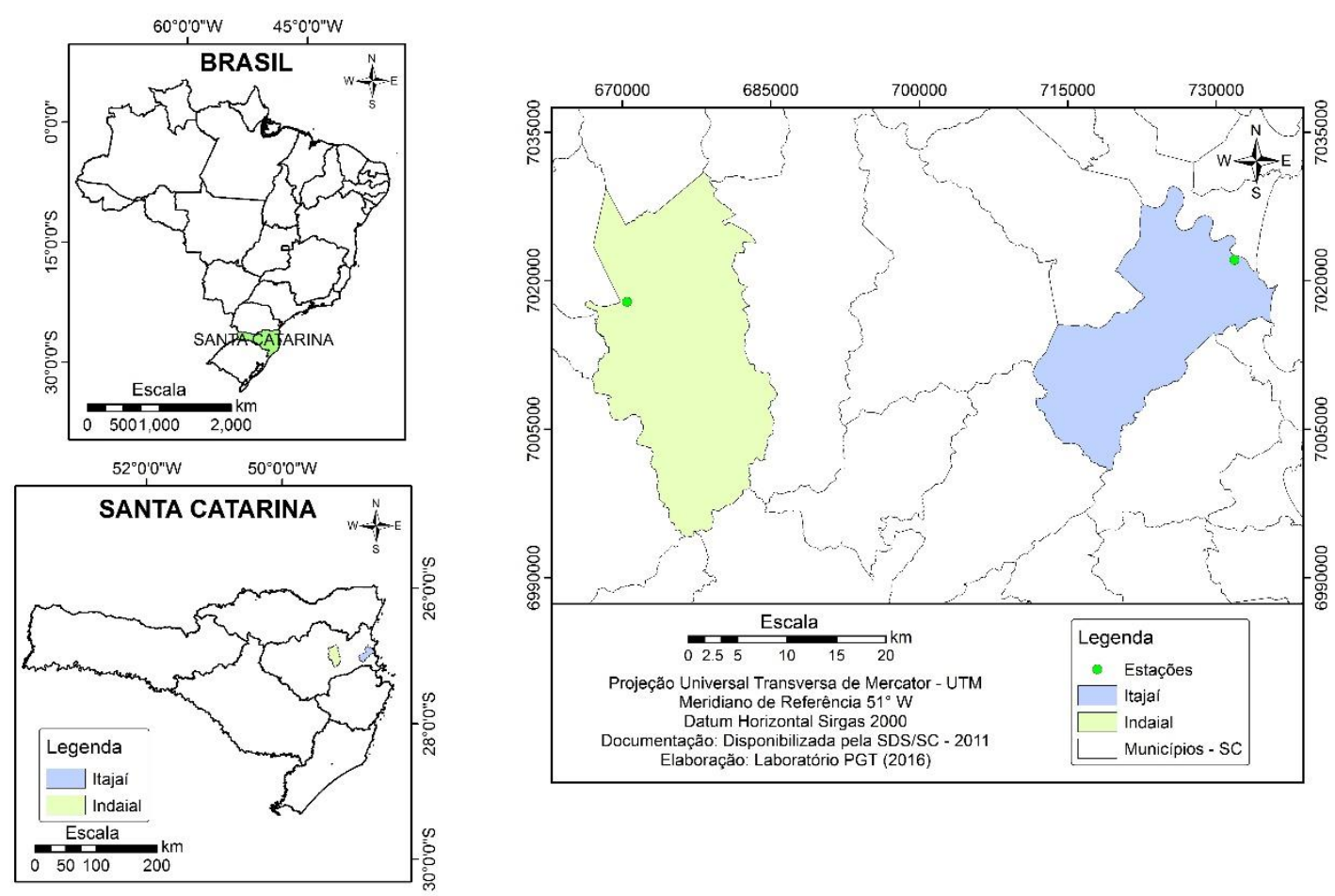

Fonte: Laboratório de Planejamento e Gestão Territorial (LabPGT/UNESC) (2016).

O clima da região em estudo, de acordo com a classificação de Köppen, é classificado como mesotérmico, sem estação seca definida e com verão quente (Cfa). Pelo Zoneamento Agroecológico e Socioeconômico de Santa Catarina (Thome et al., 1999) os municípios de Indaial e Itajaí estão inseridos na região 1A, de domínio Climático "Subquente", subdomínio climático "Superumido", variedade climática "Sem seca" e tipo climático "Subtropical” A precipitação média anual varia de 1430 a 1908 mm, com 156 a 185 dias de chuva no ano. A evapotranspiração anual varia de 936 a 1008 mm. Nos municípios localizados mais a montante da bacia o tipo climático é $2 \mathrm{~A}$, de domínio Climático "mesotérmico brando", subdomínio climático "Superumido", variedade climática "Sem seca" e tipo climático “Temperado 2". A precipitação média anual varia de 1320 a 1640 mm, com 130 a 165 dias de chuva no ano. A evapotranspiração anual varia de 794 a 937 mm (Braga e Ghellre, 1999).

Os pluviogramas foram digitalizados e com um programa de computador elaborado foram realizados os cálculos seguindo os procedimentos descritos abaixo:

1) Identificação da chuva individual: adotando os critérios sugeridos por Wischmeier \& Smith (1958), descritos em Cabeda (1976), em que foi considerada chuva individual aquela 
separada da anterior e da posterior por um período mínimo de $6 \mathrm{~h}$ sem chuva ou com menos de $1 \mathrm{~mm}$;

2) Identificação da chuva erosiva: foram consideradas chuvas erosivas aquelas com quantidade igual ou superior a $10 \mathrm{~mm}$ ou igual ou superior a $6 \mathrm{~mm}$ em um período máximo de $15 \mathrm{~min}$;

3) Cálculo da Energia cinética unitária: a energia cinética unitária de cada segmento uniforme de chuva foi obtida pela expressão proposta por Wischmeier \& Smith (1978) em unidades do sistema internacional:

$$
\mathrm{EC}=0,119+0,0873 \log \mathrm{i}
$$

Sendo: EC a energia cinética unitária $\left(\mathrm{MJ} \mathrm{ha}^{-1} \mathrm{~mm}^{-1}\right)$; i é a intensidade da chuva dada em $\mathrm{mm} \mathrm{h}^{-1}$ no segmento considerado;

Segundo Foster et al. (1981), o diâmetro das gotas de chuva não aumenta quando as intensidades são iguais ou superiores a $76 \mathrm{mmh}^{-1}$, e dessa forma a energia cinética passa a ter o valor máximo de $0,283 \mathrm{MJ} \mathrm{ha}^{-1} \mathrm{~mm}^{-1}$.

4) Cálculo da energia cinética do segmento expressa em $\mathrm{MJ} \mathrm{ha}^{-1}$, multiplicando a EC pela quantidade de chuva no respectivo segmento uniforme, isto é:

$$
\mathrm{Ecs}=\mathrm{EC} \mathrm{h}
$$

Em que: Ecs é a energia cinética do segmento $\left(\mathrm{MJ} \mathrm{ha}^{-1}\right)$; $\mathrm{h}$ é a altura pluviométrica do segmento $(\mathrm{mm})$;

5) Cálculo da energia cinética total da chuva, somando-se a energia cinética de cada segmento uniforme, isto é:

$$
\mathrm{EC}_{\mathrm{t}}=\sum \mathrm{ECs}
$$

6) Cálculo da intensidade máxima da chuva em um período de 30 min ( $\left(\mathrm{I}_{30}\right)$;

7) Determinação do índice $\mathrm{EI}_{30}$ que representa a erosividade de cada chuva individual e erosiva através da seguinte expressão, conforme Cassol et al. (2007):

$$
\mathrm{EI}_{30}=\mathrm{EC}_{\mathrm{t}}
$$

Em que: $\mathrm{EI}_{30}$ é o índice de erosividade da chuva erosiva individual ( $\mathrm{MJ} \mathrm{mm} \mathrm{ha}^{-1} \mathrm{~h}^{-1}$ ); $\mathrm{EC}_{\mathrm{t}}$ é a energia cinética total da chuva $\left(\mathrm{MJ} \mathrm{ha}^{-1}\right) ; \mathrm{I}_{30}$ é a intensidade máxima média de precipitação em $30 \mathrm{~min}\left(\mathrm{~mm} \mathrm{~h}^{-1}\right)$;

8) Obtenção das somas mensais e anuais dos índices $\mathrm{EI}_{30}$ determinados para cada chuva individual e erosiva.

Para a análise dos resultados de erosividade da chuva foi utilizada a classificação adotada por Santos (2008), conforme a Tabela 2. 
Tabela 2. Classes de erosividade da chuva média anual e mensal.

\begin{tabular}{lll}
\hline Classe de erosividade & \multicolumn{2}{c}{ Valores de erosividade } \\
\cline { 2 - 3 } & $\mathrm{MJ} \mathrm{mm} \mathrm{ha} \mathrm{h}^{-1} \mathrm{ano}^{-1}$ & $\mathrm{MJ} \mathrm{mm} \mathrm{ha} \mathrm{h}^{-1} \mathrm{mes}^{-1}$ \\
\hline Muito baixa & $\mathrm{R}<2500$ & $\mathrm{R}<250$ \\
Baixa & $2500<\mathrm{R}<5000$ & $250<\mathrm{R}<500$ \\
Média & $5000<\mathrm{R}<7000$ & $500<\mathrm{R}<700$ \\
Alta & $7000<\mathrm{R}<10000$ & $700<\mathrm{R}<1000$ \\
Muito alta & $\mathrm{R}<10000$ & $\mathrm{R}<1000$ \\
\hline
\end{tabular}

Fonte: Santos, 2008.

Para a utilização das séries pluviométricas foram correlacionados os índices de erosividade médios mensais com os valores do coeficiente de chuva (Rc), obtido conforme a proposição de Fournier (1956), modificada por Lombardi Neto (1977), com base nos valores de precipitação mensal média e precipitação anual média.

$$
R c=\frac{p^{2}}{P}
$$

em que: $\mathrm{Rc}=$ coeficiente de chuva, em $\mathrm{mm} ; \mathrm{p}=$ precipitação mensal média, em $\mathrm{mm}$; e $\mathrm{P}=$ precipitação anual média, em mm.

Foram testados os modelos linear e potência conforme:

$$
\begin{aligned}
& E I_{30}=a R c+b(6) \\
& E I_{30}=a R c^{b}(7)
\end{aligned}
$$

Em que a e b são coeficientes ajustados para cada estação.

Também foram estimados os valores do índice de concentração da precipitação (PCI) dado por:

$$
P C I=100 \frac{\sum_{1}^{12} P_{i}^{2}}{\left(\sum_{1}^{12} P i\right)^{2}}(8)
$$

Onde Pi é a precipitação mensal do mês i.

De acordo com Oliver a interpretação dos valores de PCI pode ser de acordo com a Tabela 3. 
Tabela 3. Classificação da distribuição da precipitação de acordo com o Índice de Concentração da Precipitação (PCI)

\begin{tabular}{|c|c|}
\hline PCI & Classificação \\
\hline $\mathrm{PCI}<10$ & Distribuição da precipitação uniforme (baixa concentração) \\
\hline $11<$ PCI $<15$ & Moderada concentração da precipitação \\
\hline $16<\mathrm{PCI}<20$ & Distribuição irregular \\
\hline $\mathrm{PCI}>20$ & $\begin{array}{l}\text { Indica distribuição fortemente irregular (alta concentração da } \\
\text { precipitação }\end{array}$ \\
\hline
\end{tabular}

Fonte: Oliver, 1980.

\section{RESULTADOS}

Nas Figuras 2 e 3, constam as análises de regressão dos valores de $\mathrm{EI}_{30}$ e o coeficiente de chuva para Indaial e Itajaí, respectivamente. O melhor ajuste foi obtido com a equação linear tanto para Indaial $\left(\mathrm{R}^{2}=0,709\right)$ quanto para Itajaí $\left(\mathrm{R}^{2}=0,8152\right)$. Bertol $(1993)$ e Bertol (1994) analisado dados de Lages (SC) e Campos Novos (SC) também observaram que o modelo linear foi mais adequado, enquanto que Lombardi Neto (1977) analisando dados de Campinas (SP), Carvalho (1987) analisando dados de Mococa (SP) e Sosa (1987) analisando dados de Pindorama (SP) constataram que o modelo potencial foi mais adequado. Os valores de $\mathrm{R}^{2}$ obtidos neste trabalho também são coerentes com os valores observados por outros autores. Gonçalves et al. (2006) trabalhando com catorze estações pluviográficas do estado do Rio de Janeiro encontraram valores do coeficiente $R^{2}$ variando de 0,40 a 0,98. Medina (1990) obteve $\mathrm{R}^{2}$ de 0,52 e ressalta que embora as correlações não tenham sido elevadas, foram significativas pelo teste t ao nível de significância de1\%. Silva et al. (1997) ressaltam que as correlações significativas indicam que o coeficiente de chuva pode ser usado para estimar a erosividade da chuva na ausência de dados pluviográficos. No entanto ressaltam que o uso destas equações está limitado a regiões que apresentam a magnitude dos parâmetros semelhantes aos dos empregados no ajuste das equações.

Embora as séries de dados pluviográficos disponível neste estudo foram relativamente curtas e com muitas falhas ainda se obteve valores de coeficiente de determinação aceitáveis e estatisticamente significativos. No caso da estação de Itajaí observou-se que no período analisado os valores de precipitação registrados foram abaixo da média da região e os valores de Rc foram abaixo de 25. Estes dados devem ser utilizados com ressalva.

$\mathrm{Na}$ Tabela 4 constam os valores de precipitação média mensal observada e da erosividade estimada com as equações de regressão ajustadas para cada local. Em Indaial nos meses de setembro a fevereiro a precipitação média é superior a $140 \mathrm{~mm}$, com maior valor de 229,6 mm observada em janeiro. A precipitação média anual é de 1705,0 mm. A erosividade 
apresenta variação semelhante com a precipitação, sendo os maiores valores ocorrem nos meses de janeiro e fevereiro. Esta constatação se justifica pela maior precipitação e também pelo fato de que nesta época do ano ocorrem maior frequência de chuva convectivas, que são caracterizadas pela alta intensidade, e assim mais erosivas. Na estação de Itajaí, a precipitação média anual foi de 1795,2 mm, com distribuição semelhante à observada em Indaial.

Figura 2: Curvas de ajuste entre o índice de erosividade $\mathrm{EI}_{30}$ médio mensal e o coeficiente de Chuva $\left(\mathrm{R}_{\mathrm{c}}\right)$ para Indaial, SC

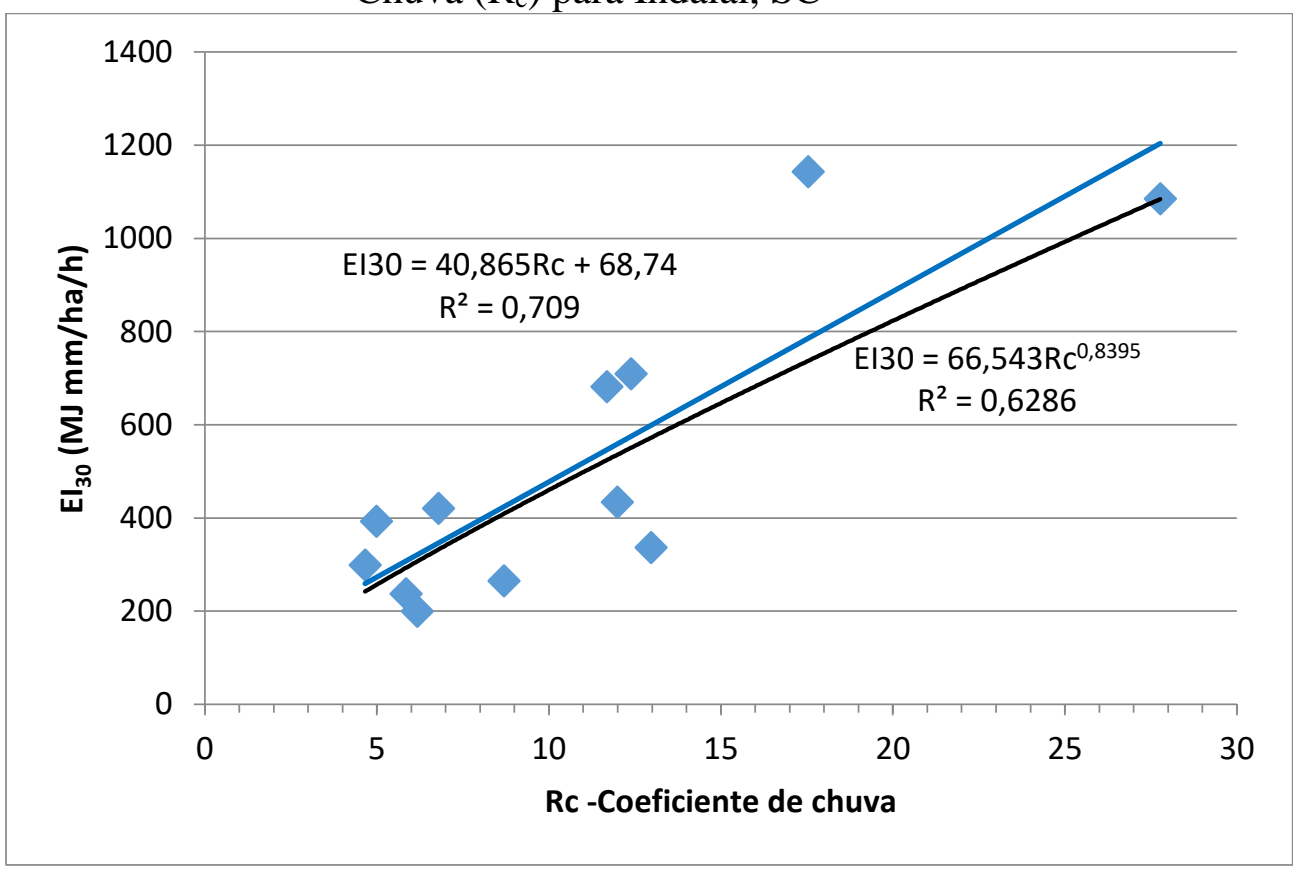

Fonte: autores, 2016

Figura 3: Curvas de ajuste entre o Índice de Erosividade $\mathrm{EI}_{30}$ médio mensal e o coeficiente de chuva $\left(R_{c}\right)$ para Itajaí, $S c$.

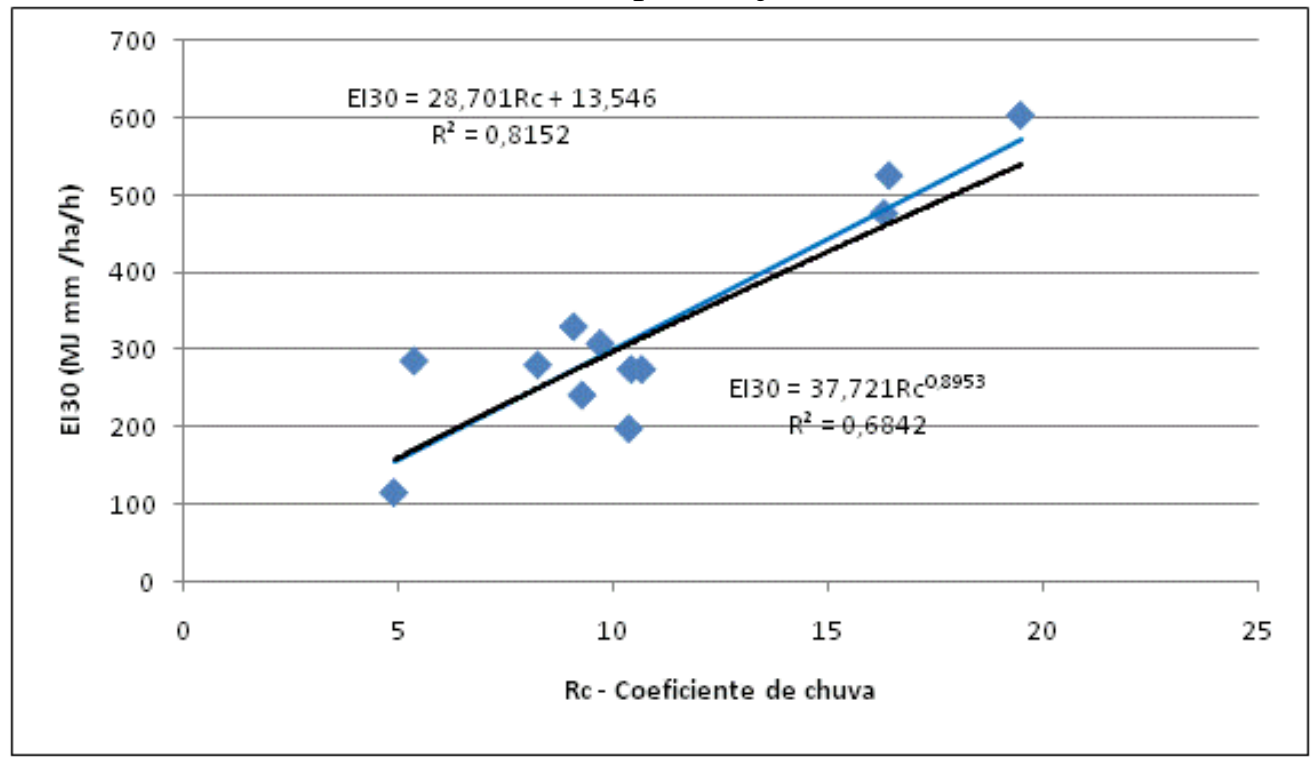

Fonte: autores, 2016. 
Tabela 4: Dados de precipitação média mensal e erosividade $\left(\mathrm{EI}_{30}\right)$ nas estações pluviométricas de Indaial e Itajaí

\begin{tabular}{lcccc}
\hline Período & \multicolumn{2}{c}{ Indaial } & \multicolumn{2}{c}{ Itajaí } \\
\cline { 2 - 5 } & $\begin{array}{c}\text { Precipitação } \\
(\mathrm{mm})\end{array}$ & $\begin{array}{c}\text { Erosividade } \\
\left(\mathrm{MJ} \mathrm{mm} \mathrm{ha}^{-1} \mathrm{~h}^{-1}\right)\end{array}$ & $\begin{array}{c}\text { Precipitação } \\
(\mathrm{mm})\end{array}$ & $\begin{array}{c}\text { Erosividade } \\
\left(\mathrm{MJ} \mathrm{mm} \mathrm{ha}^{-1} \mathrm{~h}^{-1}\right)\end{array}$ \\
\hline Jan. & 229,6 & 1332,3 & 242,8 & 955,7 \\
Fev. & 179,7 & 842,5 & 183,4 & 551,4 \\
Mar. & 148,2 & 595,3 & 173,8 & 496,3 \\
Abr. & 97,4 & 295,9 & 123,9 & 258,8 \\
Maio & 104,0 & 327,8 & 117,1 & 232,7 \\
Jun. & 112,3 & 371,1 & 109,1 & 203,7 \\
Jul. & 118,7 & 406,5 & 118,4 & 237,7 \\
Ago. & 101,8 & 317,3 & 89,5 & 141,6 \\
Set. & 153,8 & 635,7 & 157,5 & 410,1 \\
Out. & 157,1 & 660,1 & 160,1 & 423,3 \\
Nov. & 140,1 & 532,4 & 153,3 & 389,0 \\
Dez. & 163,3 & 708,1 & 166,4 & 456,0 \\
Ano & 1705,0 & 7025,0 & 1795,2 & 4756,3 \\
\hline PCI & $8,90 \%$ & - & $8,91 \%$ & \\
\hline
\end{tabular}

Fonte: autores, 2016.

A erosividade média estimada para Indaial é de $7025 \mathrm{MJ} \mathrm{mm} \mathrm{ha}^{-1} \mathrm{~h}^{-1} \mathrm{ano}^{-1}$ e para Itajaí o valor médio estimado foi de 4756,3MJ mm ha $\mathrm{Mh}^{-1} \mathrm{ano}^{-1}$. Estes valores estão coerentes com outros trabalhos de erosividade realizados no Brasil. Lombardi Neto (1977) realizou importante trabalho com registro de chuvas de 22 anos de Campinas (SP) obtendo o índice de erosividade $\mathrm{EI}_{30}$ médio de $6769 \mathrm{MJ} \mathrm{mm} \mathrm{ha}^{-1} \mathrm{~h}^{-1} \mathrm{ano}^{-1}$, sendo que 90,7\% do índice de erosividade esteve associado ao período de outubro a março, sendo que nesse período a chuva correspondente foi de 80,1\%. Cogoet al. (1978) calcularam o índice de erosividade $\mathrm{EI}_{30}$ para municípios do Rio Grande do Sul obtendo valores médios de 6275, 8606 e 7695 MJ mm ha ${ }^{-1}$ $\mathrm{h}^{-1}$ ano $^{-1}$. Lago (1984) analisando série de 25 anos de dados de pluviógrafo de Pelotas (RS) obteve valor médio de $3484 \mathrm{MJ} \mathrm{mm} \mathrm{ha}^{-1} \mathrm{~h}^{-1} \mathrm{ano}^{-1}$. Gonçalves et al. (2006) trabalhando com várias estações do Rio de Janeiro encontraram valores médios variando de 4118 a 16225 MJ $\mathrm{mmha}^{-1} \mathrm{~h}^{-1}$ ano $^{-1}$. Valvassori e Back (2014) analisando série de dados do período de $1980 \mathrm{a}$ 2011 registrados no pluviógrafo de Urussanga, localizada no Sul do estado de Santa Catarina, encontraram valores de $\mathrm{R}$ variando de $2847 \mathrm{MJ} \mathrm{mmha}^{-1} \mathrm{~h}^{-1} \mathrm{ano}^{-1} \mathrm{a} 12091 \mathrm{MJ} \mathrm{mmha}^{-1} \mathrm{~h}^{-1} \mathrm{ano}^{-1}$, com média de $5665 \mathrm{MJ} \mathrm{mmha}^{-1} \mathrm{~h}^{-1}$ ano $^{-1}$. Outros trabalhos sobre erosividade para Santa Catarina foram realizados por Bertol (1993) e Bertol (1994), que encontraram valores de 5694 MJ mmha ${ }^{-1} \mathrm{~h}^{-1}$ ano $^{-1}$ e $6329 \mathrm{MJ} \mathrm{mmha}^{-1} \mathrm{~h}^{-1}$ ano $^{-1}$, respectivamente para Lages e para Campos Novos. 
A erosividade média anual de Indaial é classificada como "Alta" enquanto que a erosividade de janeiro foi classificada como "Muito alta e em fevereiro como "Alta". Para os meses de março e setembro a dezembro a erosividade é classificada como "Média" e nos demais meses como "Baixa". Para Itajaí a erosividade anual classificada como "Média". Dos valores mensais no mês de janeiro a erosividade foi classificada como "Muito alta" e fevereiro como "Média". Nos meses de março, abril, outubro, novembro e dezembro a erosividade é baixa, e nos meses de junho, julho e agosto a erosividade é "Muito baixa".

Nas Figuras 4 e 5 constam a distribuição acumulada da precipitação e da erosividade ao longo do ano. Em ambas as estações foram observados valores de PCI inferiores a $10 \%$ indicando baixa concentração de precipitação. Observa-se que a erosividade apresenta distribuição semelhante à precipitação, com concentração da erosividade ligeiramente superior a precipitação nos meses de janeiro e fevereiro. Em Indaial a precipitação em janeiro corresponde a 13,5\% do total precipitado e a erosão corresponde a 19,0\%da erosividade anual. Para a estação pluviométrica de Itajaí, a precipitação de janeiro corresponde a 14,3\% da precipitação anual e a erosividade corresponde a 21,9\%. Para os demais meses do ano as diferenças entre os percentuais de precipitação e erosividade são inferiores a $2 \%$.

De acordo com as Figuras 4 e 5, observa-se que nos meses de primavera e verão ocorrem maiores valores de chuvas erosivas e deve-se dar atenção especial para as práticas de conservação do solo e controle de erosão. Segundo Val et al. (1986) a variação do fator R ao longo do ano define a melhor época para o estabelecimento de práticas e manejo do solo. Bertol (1994) também ressalta que o fator $\mathrm{R}$ além de seu papel como componente da USLE pode servir ainda como parâmetros de suporte a trabalhos de extensão e assistência rural, pois permite definir épocas críticas quando a ocorrência de erosão.

$\mathrm{Na}$ bacia do Rio Itajaí existem várias atividades agrícolas realizadas em áreas de relevo ondulado e forte ondulado que oferecem riscos a erosão do solo, como por exemplo, o cultivo da cebola, feijão, milho e do fumo. Vários tipos de solo têm restrição de uso devido a declividade e sua suscetibilidade a erosão (Thomé et al., 1999) que ressaltam a importância dos trabalhos de conservação do solo e controle de erosão. 
Figura 4: Distribuição acumulada da chuva e do índice de erosividade ( $\left.\mathrm{EI}_{30}\right)$ em Indaial, SC



Fonte: autores, 2016.

Figura 5: Distribuição acumulada da chuva e do Índice de Erosividade (EI $\left.{ }_{30}\right)$ em Itajaí, SC

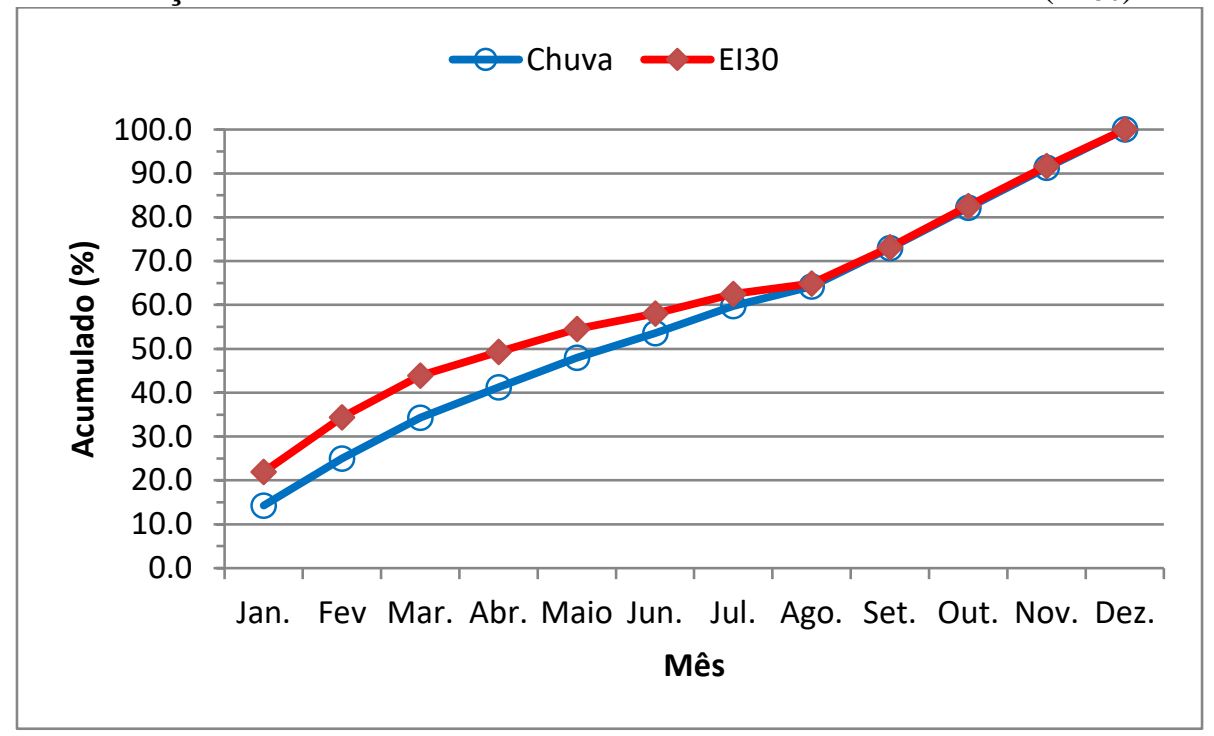

Fonte: autores, 2016.

\section{CONCLUSÕES}

Com base nos resultados obtidos neste estudo pode-se concluir que:

1) Para a estação de Indaial e Itajaí obteve-se melhor ajuste da equação de regressão entre a erosividade e o coeficiente de chuva no modelo linear;

2) A equação para a estimativa da erosividade em Indaial é dada por $\mathrm{EI}_{30}=40,86 \mathrm{RC}+$ 68,74 e para Itajaí equação é dada por $\mathrm{EI}_{30}=28,70 \mathrm{Rc}+13,54$ 
3) O fator R para uso na Equação Universal de Perdas de Solo em Indaial é de 7025,0 MJ $\mathrm{mmha}^{-1} \mathrm{~h}^{-1}$ ano $^{-1}$ e Itajaí o valor de $\mathrm{R}$ é de $4756,3 \mathrm{MJ} \mathrm{mmha}^{-1} \mathrm{~h}^{-1}$ ano $^{-1}$

4) Embora tenha sido observada ligeira concentração da erosividade nos meses de janeiro e fevereiro, existe baixa concentração da precipitação e erosividade de forma que deve manter práticas conservacionistas e de controle de erosão durante todo o ano.

5) Em Indaial a erosividade média anual foi classificada como Alta e no mês de janeiro como Muito alta e fevereiro como Alta.

6)Para Itajaí a erosividade anual classificada como "Média". Dos valores mensais no mês de janeiro a erosividade foi classificada como "Muito alta" e fevereiro como "Média".

\section{REFERÊNCIAS BIBLIOGRÁFICAS}

AGÊNCIA NACIONAL DE ÁGUAS - ANA. Inventário das estações pluviométricas. 2 ed. - Brasília: ANA; SGH, 2009.

BERTOL, I. Avaliação da erosividade da chuva na localidade de Campos Novos (SC) no período de 1981-1990. Pesquisa Agropecuária Brasileira, Brasília, v.29, n.9, p.1453-8, set. 1994.

BERTOL, I. Índice de erosividade (EI30) para Lages (SC) $-1^{\mathrm{a}}$ aproximação. Pesquisa Agropecuária Brasileira, Brasília, v.28, n.4, p.515-21, abr. 1993.

BRAGA, H. J.; GHELLRE, R. Proposta de diferenciação climática para o estado de Santa Catarina. In: CONGRESSO BRASILEIRO DE AGROMETEOROLOGIA, 11. 1999, Florianópolis, Anais... Florianópolis, SC. 1999. p.1761-1769

CABEDA, M.S.V. Computation of storm EI value. West Lafayette: Purdue University, 1976. 6p.

CASSOL, E. A. Erosão do solo: influência do uso agrícola, do manejo e preparo do solo. 2. ed. Porto Alegre: IPRNR, 1986. 40 p.

CASSOL, E. A.; MARTINS, D.; ELTZ, F. L. F.; LIMA, V. S. de; BUENO, A. C. Erosividade e padrões hidrológicos das chuvas de Ijuí(RS) no período de 1963 a 1993. Revista Brasileira de Agrometeorologia, v.15, n.3, p.220-231, 2007.

CARVALHO, M.P. Erosividade da chuva: distribuição e correlação com as perdas de solo de Mococa - SP. Piracicaba, SP: USP, 1987. 104 f. Dissertação (Mestrado em Solos e Nutrição de Plantas) - Escola Superior de Agricultura "Luiz de Queiroz", Universidade de São Paulo, Piracicaba.

COGO, N. P.; DREWS, C. R.; GIANELLO, C. Índice de erosividade das chuvas dos municípios de Guaíba, Ijuí e Passo Fundo, no Estado do Rio Grande do Sul. In: ENCONTRO

NACIONAL DE PESQUISA SOBRECONSERVAÇÃO DO SOLO, 2., 1978, Passo Fundo. Anais... Passo Fundo, RS: CNTRIGO; EMBRAPA; SNLCS, 1978. p.145-52.

FOSTER, G. R.; McCOOL, D. K.; RENARD, K. G.; MOLDENHAUER, W. C. Conversion of the universal soil loss equation to SI units. Journal of Soil and Water Conservation, Baltimore, v. 36, p. 355-9, 1981. 
FOURNIER, F. The effect of climatic factors on soil erosion estimates of solids transported in suspension in runoff. [S.1.]: Association HydrologicInt. Public, 1956. v.38, 6 p.

GONÇALVES, F. A.; SILVA, D.D. da; PRUSKI, F.F.; CARVALHO, D.F. da; CRUZ, E.S. da. Índices e espacialização da erosividade das chuvas para o Estado do Rio de Janeiro. Revista Brasileira de Engenharia Agrícola e Ambiental, v.10, n.2,p.269-276, 2006.

LAGO, J. C. Erosividade das chuvas de Pelotas. In: ENCONTRO NACIONALDE PESQUISA SOBRE CONSERVAÇÃO DO SOLO, 5., 1984, Porto Alegre. Resumos...Porto Alegre, SBCS, 1984. p. 72.

LOMBARDI NETO, F. Rainfall erosivity - Its distribution and relationship with soil loss at Campinas, Brazil. West Lafayette: Purdue University, 1977. 53 p.(M.Sc. Thesis).

MEDINA, B.F.; OLIVEIRA JÚNIOR, R.C. A aplicabilidade de alguns índices erosivos em Latossolo Amarelo de Manaus (AM). Revista Brasileira de Ciência do Solo, Campinas, v.11, n.1, p.67-70, 1987.

OLIVER, J. E. Monthly precipitation distribution: A comparative index. The Professional Geographer. v.32, p.300-309, ago 1980.

PRUSKI, F. F. (Ed.) Conservação do solo e água: práticas mecânicas para o controle da erosão hídrica. 2. ed. Viçosa: UFV, 2009. 279 p.

SANTOS, C.N. El Niño, La Niña e a erosividade das chuvas no Estado do Rio Grande do Sul. Universidade Federal de Pelotas, Faculdade de Agronomia Eliseu Maciel, Programa de Pós-graduação em Agronomia. 2008.

SILVA, M. L. N.; FREITAS, P. L.; BLANCANEAUX, P.; CURI, N. Índices de erosividade das chuvas da região de Goiânia, GO. Revista Brasileira de Ciência do Solo, v.32, n.10, p.275-89, 1997.

SOSA, D. A. Erosividade da chuva. Distribuição e correlação com as perdas de solo para Pindorama, São Paulo, Brasil. Piracicaba, SP: ESALQ, 1987.105 f. Dissertação (Mestrado em Agronomia) - Escola Superior de Agricultura "Luiz de Queiroz", Piracicaba.

THOME, V. M. R.; ZAMPIERI, S. BRAGA, H. J.; PANDOLFO, C.; SILVA JUNIOR, V. P. da; BACIC, I.; LAUS NETO, J.; SOLDATELI, D.; GEBLER, E.; ORE, J. D.; ECHEVERRIA, L.; MATTOS, M.; SUSKI, P. P. Zoneamento Agroecológico e Socioeconômico de Santa Catarina. Florianópolis, 1999. CD-ROOM

VAL, L.A.; BAHIA, V.G.; FREIRE, J.C.; DIAS JÚNIOR, M.S. Erosividade das chuvas em Lavras, MG. Ciência e Prática, Lavras, v.10, n.2, p.199-209. 1986.

VALVASSORI, M.L; BACK, Á. J. Avaliação do potencial erosivo das chuvas em Urussanga, SC, no período de 1980 a 2012. Revista Brasileira de Ciência do Solo, v.38, p.1011-1019, 2014.

WISCHMEIER, W. H.; SMITH, D. D. Rainfall energy and its relationship to soil loss. Transaction American Geophysical Union, Washington, v.39, n.2, p.285-91, 1958.

WISCHMEIER, W. H.; SMITH, D. D. Predicting rainfall erosion losses: a guide to conservation planning. Washington, DC: USDA, 1978. 58p. Agriculture Handbook 537.

WISCHMEIER, W. H.; SMITH, D. D. Predicting rainfall-erosion losses from cropland east of the Rocky Mountains: Guide for selection of practices for soil and water conservation. Washington, DC: USDA, 1965. 47p. Agricultural Handbook 282. 
Revista Tecnologia e Ambiente, v. 23, 2017, Criciúma, Santa Catarina/SC

ISSN Eletrônico 2358-9426 e ISSN Impresso 1413-8131

\section{AGRADECIMENTOS}

Os autores agradecem ao Conselho Nacional de Desenvolvimento Cientifico e Tecnológico (CNPq) pelo apoio financeiro a esta pesquisa. 